\title{
REPRESENTAÇÕES SOCIAIS DE ADOLESCENTES E JOVENS ACERCA DA RELAÇÃO SEXUAL E DO USO DO PRESERVATIVO.
}

\author{
Bruno A. P. Dala ${ }^{1}$ \\ https://orcid.org/0000-0002-8961-6535
}

\section{RESUMO}

El presente estudo busca conocer las Representaciones Sociales sobre relación sexual y uso de preservativo en adolescentes y jovenes. Se utilizó como referencial teórico la teoria dimensional ou procesual de Denise Jodelet (2001) y Moscovici (2007), la teoria del núcleo central de Jean-Claude Abric (2001) y la teoria societal de Willem Doise (2002). Se utilizó la pesquisa quali-quantitativa de carácter exploratória. La amuestra fue no-probabilística por conveniencia constituída por 79 estudiantes de dos escuelas públicas. Los participantes respondieron a una encuesta y a un Teste de Asociación Libre de Palavras con tres estímulos inductores: sexo, sexo sin condon (preservativo) y sexo com condon. Los datos fueron tratados con auxílio del software IBM SPSS Statistic y el openEvoc 0.84. El análisis de los resultados revela que os adolescentes y jovenes relacionam sexo con prazer, intimidad y amor y la no utilización del condon con peligro, gravidez, enfermedad, HIV. Se concluye que los adolescentes y jovenes poseen informaciones sobre los peligros de la no utilización del preservativo, no obstante, para ellos el uso del preservativo diminuye el placer sexual.

Palavras-chave: Representação social; doenças sexualmente transmissíveis; Adolescência; Preservativo.

\section{Representaciones sociales de adolescentes y jóvenes acerca de la relación sexual y el uso del preservativo}

\section{RESUMEN}

El presente estudo busca conocer las Representaciones Sociales sobre relación sexual y uso de preservativo en adolescentes y jovenes. Se utilizó como referencial teórico la teoria dimensional ou procesual de Denise Jodelet (2001) y Moscovici (2007), la teoria del núcleo central de Jean-Claude Abric (2001) y la teoria societal de Willem Doise (2002). Se utilizó la pesquisa quali-quantitativa de carácter exploratória. La amuestra fue no-probabilística por conveniencia constituída por 79 estudiantes de dos escuelas públicas. Los participantes respondieron a una encuesta y a un Teste de Asociación Libre de Palavras con tres estímulos inductores: sexo, sexo sin condon (preservativo) y sexo com condon. Los datos fueron tratados con auxílio del software IBM SPSS Statistic y el openEvoc 0.84. El análisis de los resultados revela que os adolescentes y jovenes relacionam sexo con prazer, intimidad y amor y la no utilización del condon con peligro, gravidez, enfermedad, HIV. Se concluye que los adolescentes y jovenes poseen informaciones sobre los peligros de la no utilización del preservativo, no obstante, para ellos el uso del preservativo diminuye el placer sexual.

Palabras clave: representacion social; enfermedades de transmision sexual; adolescencia; preservativo.

Social representations of adolescents and young people about sexual intercourse and condom use

\section{ABSTRACT}

This study aims to know the Social Representations on sexual intercourse and condom use in adolescents and young people. The theoretical or procedural theory of Denise Jodelet (2001) and Moscovici (2007), the Central Core Theory of Jean-Claude Abric (2001) and Willem Doise's Societal Theory (2002) was used as a theoretical framework. Exploratory qualitative and quantitative research was used. The sample was non-probabilistic for convenience, consisting of 79 students from two public schools. Participants answered a questionnaire and a Free Word Association Test with three inducing stimuli: sex, sex without a condom and sex with a condom. The data were processed with the help of IBM SPSS Statistic and openEvoc 0.84 software. The analysis of the results showed that adolescents and young people relate sex to pleasure, intimacy and love and not using a condom with danger, pregnancy, illness, HIV. It was concluded that adolescents and young people have information about the dangers of not using condoms, however, for them, condom use decreases sexual pleasure.

Keywords: Social representation; sexually transmitted diseases; Adolescence; Condom.

\footnotetext{
${ }^{1}$ Licenciado em Psicologia Social. Mestrando em Comunicação e Marketing. Luanda, Angola. Email: bruno.apolinario.pinto@gmail.com
} 


\section{Introdução}

A Organização Mundial de Saúde (OMS) define a adolescência como o período compreendido entre os 10 e 19 anos (Neto \& Cerqueira-Santos, 2012). Porém, para alguns autores, estas idades variam consoante aspectos culturais, género, características pessoais e outros aspectos, por exemplo, na cultura ocidental, a adolescência para as meninas começa entre 11 e 12 anos, que corresponde ao surgimrnto da "primeira menstruação, menarca"(Campagna, 2005).

Muitos autores veêm a adolescência como uma fase marcadas com profundas alterações biológicas, psicológicas e socioculturais, começando com a puberdade, que é a fase de transformações biológicas importantes no processo de maturação dos órgãos sexuais primários e secundários, terminado com a "autonomia" ou independência social do adolescente e jovens.

Para Rodrigues (2010), por exemplo, a adolescência é uma fase que se encontra entre a "infância" e a vida "adulta", decorre num processo de maturação dos órgãos sexuais e termina com a inserção do adolescente na vida social. Nesta fase, aparece um estímulo interno forte para estabelecer relações com os outros, principalmente para a consumação do acto sexual. Fenómeno que faz parte de uma dimensão maior que é chamada de sexualidade.

A sexualidade e sua manifestação são inerentes ao ser humano. De acordo com Itoz (2012), não podemos compreender a sexualidade sem levar em conta o factor "biológico, o psicossociológico, o religioso", a afectividade e outras dimensões pessoais. Porém, para a psicanálise a sexualidade envolve uma área abrangente que ultrapassa o aspecto biológico e o psicológico, envolvendo o prazer, erotismo, o afecto, as relações e toda variável qualitativa e quantitativa do prazer (Queiroz et al. 2015).

A manifestação da sexualidade e a busca por parte do adolescente e jovem por contacto social, o leva a enfrentar diversos problemas como a gravidez indesejada, "abuso de drogas", baixo rendimento escolar, delinquência juvenil, exploração sexual e baixa autoestima. Face a esses problemas, é necessário que se criem políticas públicas viradas para os adolescentes e jovens, isto é, diferentes das viradas para os adultos, levando em conta aspectos sociais, locais de interacção, ambientes sociais, "formação e intervenção", bem como aspectos familiares "influenciados" pelo meio social e cultural. (Neto \& Cerqueira-Santos, 2012)

Sendo assim, as representações sociais dos adolescentes e jovens são importantes pois permite investigar, compreender e intervir nos múltiplos problemas que os adolescentes enfrentam, sobretudo nas questões relacionadas com doenças particularmente o HIV (Ribeiro, Coutinho \& Saldanha, 2004).

O presente artigo pretende conhecer as representações sociais de sexualidade em adolescentes e jovens, sendo a sexualidade uma área que envolve diversos aspectos, buscamos conhecer a estrutura das representações dos adolescentes e jovens de escolas públicas sobre sexo e uso de preservativo. Os objetivos basearam-se nas palavras que os adolescentes e jovens de duas escolas públicas relacionaram com os termos sexo, sexo sem preservativo e sexo com preservativo, chamados termos indutores.

Os resultados demonstrados e a discussão dos dados fazem parte de um estudo com abordagem quali-quantitativa, baseado nos estudos de Abric (2001) sobre o núcleo central das representações sociais.

Baseado na amostragem não-probabilista, os dados foram colectados por um questionário contendo três palavras indutoras através das quais os inquiridos deveriam escrever as cinco palavras que lhes viessem a mente, posteriormente os dados colectados foram categorizados pela planilha do Excel e interpretados pela plataforma openEvoc 0.84 que fornece quatro casas sobre a estrutura das representações sociais, os dados sócio-demográficos e os relacionados com o comportamento sexual foram tratados pelo software IBM SPSS Statistic v.24.

A presente pesquisa está dividida em cinco partes. Posterior a introdução, está a primeira parte sobre adolescência e comportamento sexual, onde se pretendeu caracterizar a adolescenciajuventude e os comportamentos sexuais-reprodutivos. Na segunda parte, fez-se uma resenha histórica sobre as representações sociais, suas abordagens com base nos autores mais 
representativos, bem como alguns estudos sobre as representações sociais na comunidade dos Países de Língua Portugesa (CPLP). Na terceira parte, o da metodologia, clareou-se os métodos, procedimentos e técnicas utilizadas na pesquisa. Na quarta parte parte, a dos resultados e discussão, caracterizou-se a amostra, o local de estudo e posteriormente touxe-se os resultados da pesquisa. Por fim, descrevemos algumas considerações extraídas com base na pesquisa realizada.

\section{Adolescência e comportamento sexual}

Como se viu, adolescência é uma fase que devido a sua particularidade, a adolescência requer mais "atenção" por parte dos progenitóres e da escola, principalmente nas sociedades modernas (Zampieri, 2004), pois normas criadas em nossa sociedade para "sancionar" o comportamento sexual foram quebradas, ou seja, a relação sexual antes do casamento era, outrora, punível, todavia, nas sociedades actuais, não só os adolescentes e jovens, mas muitos pais mudaram sua visão sobre este assunto (Zampieri, 2004; Manning, 1993).

Oliveira et al. (2009), afirmam que nas sociedades actuais, é cada vez mais frequente o começo da vida sexual durante a adolescência, fase em que muitos adolescentes não são maduros, responsáveis, exeprientes e informados, tanto pela escola com pela família, o suficiente em matéria de sexo, podendo resultar numa gravidez não planeada, aborto sem segurança ou numa doença sexualmente transmissível.

Consequentemente, pode-se ver no índice de natalidade de jovens de 14 a 19 anos que cresceram nos últimos vinte anos, isto devido a "pressão" do parceiro, a "expectativa social" existente, os padrões de "valores" comportamentais, pois os adolescentes e jovens são impelidos a começar a prática sexual, e esse é apenas um dos "indicadores" da lacuna que existe entre aquisição de "informações" e a prática delas (Aquino, 1997; Rodrigues, 2010).

$\mathrm{O}$ aumento de adolescente e jovens com infecções sexualmente transmissível como o HIV/sida e com gravidez precoce, faz com que os adolescentes e jovens sejam vulneráveis no que concerne a "saúde sexual e reprodutiva".

Estudos, por exemplo, mostram que os rapazes iniciam a vida sexual mais cedo que as meninas e têm, de igual modo, mais parceiros sexuais (Rodrigues, 2010).

A escola visa desenvolver competências, formar os jovens e ajudar nas tomadas de decisões, razão pela qual, ela torna-se no melhor parceiro para auxiliar os pais que temem pela vida de seu filhos. Aquino (1997) defende que muitas instituições escolares, sabendo da sua "responsabilidade social" são "pressionadas" pelos encarregados, fazendo com que procurem incluir em prática a chamada "orientação sexual".

\section{Representações sociais}

O estudo das representações sociais surgiu da Sociologia com o trabalho de Émile Durkheim, com o termo "representações colectivas". Durkheim (2007) acreditava que as representações não tinham a sua origem no psiquismo do homem, todavia eram oriundas dos aglomerados sociais. Durkheim fez entender o conceito de representações colectivas, sua utilidade e quais fenómenos as representações constituem.

De acordo com Vala e Monteiro (1993), para Durkheim as representações sociais são resultados da sociedade e estão acima dos seres humanos como uma força externa e que formam fenómenos muito diversos como a religião, a ciência, os mitos e o senso comum servindo, assim, para a coesão social. Como podemos notar, Durkheim demonstrou as representações de um ângulo da sociologia, porém, foi com Moscovici que as representações ganham espaço na área da Psicologia Social.

Segundo Moscovici (2007), Durkheim trouxe-nos o conceito de representações sociais, num visão sociológica, mas a Psicologia social abordá-a em um ângulo distinto da sociologia, pois ela entende as representações sociais como elemento para ser descrito e não fragmentado para posteriormente ser analisado. 
Assim, Representações sociais são conhecimentos da vida quotidiana, "crenças e ideologias", resultantes de processos cognitivos, formados mediante a um "objecto social", partilhados por indivíduos de uma determinada sociedade (Jovchelovitch, 2000; Myers, 2014; Jodelet, 2001; Sá, 1996).

\section{Teorias sobre as Representações sociais}

A “Teoria das Representações sociais" desmembra-se em três abordagens que se complementam uma a outra, explicando melhor uma determinada representação social. (Almeida, 2009). Estas teorias são: Teoria dimensional ou processual de Denise Jodelet, Teoria do Núcleo Central de Jean-Claude Abric e a teoria Societal de Willem Doise.

A abordagem dimensional ou processual desenvolvida por Jodelet, afirma que é imprescindível que o indivíduo tome conhecimento acerca do seu arredor. E que crie as representações sociais, não só para se encaixar no mundo, mas porque carece de saber de como agir perante a realidade, controla-lo de modo real ou mental, reconhecer e dar solução as situações que vão surgindo (Jodelet, 2001).

Os principais fenómenos que sustentam esta teoria são a ancoragem e objectivação. De acordo com Moscovici (2007), a ancoragem é um processo que muda qualquer coisa estranha e incómodo, que perturba nossa categoria individual e o equipara com um modelo que nos é conveniente enquanto a objectivação liga a ideia de "não-conhecido" com aquilo que se conhece, com o que se possui no sistema cognitivo, e se transforma em parte da existência do indivíduo. A teoria de Jodelet traz conceitos importantes que nos proporcionam bases para analisar as representações sociais.

A Teoria Societal desenvolvida por Willem Doise, tem como objectivo ligar as explicações dos indivíduos a explicações da sociedade, revelando assim, como o indivíduo traz consigo processos que fazem com que ele actue na sociedade e, de uma forma integral, oriente a modo de como agem tais processos (Doise, 2002). Assim, para essa teoria, o indivíduo está intimamente ligado com a sociedade, que de acordo com Mendonça e Lima (2014) ocupa uma visão mais sociológica, destacando a inclusão social do indivíduo como causador de alteração dessas representações.

Já a Teoria do Núcleo Central surgiu com a tese de Doutoramento de Abric em 1976, para explicar como estão organizadas as representações internamente.

De acordo com Abric, não há "realidade objectiva", porém toda realidade é "representada", absorvida pelo sujeito ou pela sociedade e reorganizada em seu "sistema cognitivo", incluida no seu "sistema de valores" que varia com a sua "história", a sua realidade social e ideológica que está a sua volta. E é essa "realidade" absorvida e reformulada que compõem a "realidade" em si (Abric, 2016).

Um aspecto importante é o facto de essa teoria ter um lugar privilegiado no estudo das teorias das representações sociais, pois ao contrário das demais teorias que tratam dos aspectos externos, Abric e Flament mostram como está organizada e estruturada as representações em seus aspectos internos. (Sá, 1996; Vala, 1993).

Nas representações sociais estão contidas dois sistemas de significações sociais: "o sistema periférico" e o "sistema central", os sistemas periféricos são mais subjectivos, flexíveis, diferenciam o grupo e protegem o "núcleo central". Enquanto o "sistema central" é estável, traz a união e coesão do grupo.

Abric afirma que toda "representação" é estruturada em volta de um "núcleo central", formada por um ou mais componente que dão sentido a "representação", ela é importante para conhecer o objecto representado, contudo, os "elementos periféricos" são estruturados em volta do "núcleo central", eles inserem "informações" guardadas, "selecionadas" e decifradas em relação ao "objecto", contexto social, "estereótipo" e "crenças" (Abric, 2001). 


\section{Estudos sobre as representações sociais}

Os estudos sobre as representações sociais vêm sendo realizados em muitos países, principalmente em Angola, visto que ela é importante para explicar a conduta das pessoas no seu quotidiano, bem como o conceito que as pessoas têm sobre uma situação ou fenómeno. Entre os diversos estudos pode-se citar aqueles feitos nos Comunidade dos Países de Lígua Portuguesa (CPLP).

Em Angola, Simões (2015) realizou um estudo intitulado "representações sociais dos jovens de Luanda sobre a inclusão social", o objectivo foi analisar as representações sociais dos jovens luandenses sobre a inclusão social. Utilizou a teoria das representações sociais de Moscovici e Jodelet. A abordagem foi qualitativa, composta por 6 participantes. Os resultados evidenciam que os conceitos sobre a inclusão social muda com ou sem a presença de um programa de inclusão. Conclui-se que Aqueles que não benefiaram de algum programa de inclusão têm uma percepção crítica quanto a processo de inclusão.

Em Portugal, Batista (2006) realizou uma pesquisa com o tema "Representações Sociais construídas pelos Professores de Adolescentes Institucionalizadas". O estudo objectivou analisar os tipos de representações sociais que os professores possuem de adolescentes institucionalizados. Foi utilizado a abordagem qualitativa, participaram do estudo sete professores. O estudo concluiu que na amostra existiam docentes que possuíam representações sociais negativas de adolescentes institucionalizados, condicionando o seu desempenho e expectativas, porém foi possível depararse com o inverso, professores que têm representações sociais positivas, não aceitando que o seu desempenho e expectativa se transforma diante os alunos institucionalizados.

Por fim no Brasil, Queiroz et al. (2015) realizaram uma pesquisa que teve como tema "representações sociais da sexualidade entre idosos" que objectivou conhecer as representações sociais sobre sexualidade entre os idosos. Participaram da pesquisa 30 idosos, os dados foram tratados pelo software EVOC 2000. Os resultados mostraram que palavras como: amor, carinho e respeito fazem parte do núcleo central de sexualidade na terceira idade.

\section{Metodologia}

\section{Instrumento e procedimento}

A abordagem da pesquisa é quali-quantitativa, realizada em Luanda no Liceu n³049 e na Escola n 3081 . Na parte quantitativa utilizamos um questionário, dirigido a 53 indivíduos, que contou com perguntas fechadas relacionadas com as dimensões sócio-demográficas e ao comportamento sexual dos adolescentes e jovens, enquanto que a parte qualitativa foi composta por um Teste de Associação Livre de Palavras (TALP) com três estímulos indutores: sexo, sexo sem camisinha e sexo com camisinha, o TALP foi respondido por 79 indivíduos.

Para a selecção da amostra recorreu-se a amostragem não-probabilística por acessibilidade ou por conveniência. Neste tipo de amostragem, o investigador escolhe os indíviduos a que tem "acesso (Prodanov e Freitas, 2013). Utilizamos esse tipo de amostragem devido as burocracias das intituições em autorizar uma pesquisa científica e a dificuldade em convencer os jovens a fornecer dados sobre a temática sexualidade, visto que ela é encarado por muitos como tabu.

A amostra foi constituída por 79 estudantes de duas escolas públicas, 67,1 ( $\mathrm{n}=53$ ) dos género masculino e 32,9 ( $\mathrm{n}=26)$ do género feminino, com a média=18,46; e dp (desvio-padrão)=2,005; mínima=14; máxima $=25$.

A principio, foi entregue aos estudantes um termo de consentimento informado no qual os estudantes tinham livre arbítrio de participar ou não da pesquisa.

Nesta conformidade, utilizou-se os seguintes instrumentos: questionário composto por questões sociodemográficas por questões ligadas ao comportamento sexual e um Teste de Associação Livre de Palavras (TALP) com três estímulos indutores: sexo, sexo sem camisinha e sexo com camisinha. O Teste de Associação Livre de Palavras (TALP), que é uma técnica que permite captar os componentes de uma representação. Consiste em solicitar que os questionados mediante um "termo indutor" mostrado pelo investigador, escrevam as "palavras" que lhes vem a mente (Sá, 1996). 
Os dados coletados com o questionário foram tratados com o software de edição de dados IBM SPSS Statistic (Statistical Package for Social Sciences-Pacote Estatístico para as Ciências Sociais) versão 24 , onde se encontrou a média, desvio padrão, valor máximo e mínimo.

Os dados da TALP foram tratado com a plataforma openEvoc 0.84 e categorizado de acordo com o género, com um ponto de corte de uma frequência acima do valor igual o superior 10 e rang menor do que valor absoluto 3. A plataforma openEvoc 0.84 foi criada por Hugo Cristo (2019) e trata os dados tal como o software EVOC (Ensemble de Programmes Permettant L'analyse des Evocations) que nos fornece quatro quadros sobre o núcleo central e periféricos das representações sociais.

\section{Resultados e discussão \\ Caracterização da amostra}

Tabela 1: Distribuição da amostra conforme a idade, Luanda/Cazenga, 2019.

Fonte: elaboracion propria.

\begin{tabular}{lr}
\hline $\begin{array}{l}\text { A idade mínima dos } \\
\text { estudantes }\end{array}$ & 14 anos \\
\hline Idade Máxima & 25 anos \\
\hline $\begin{array}{l}\text { Média de Idade dos } \\
\text { estudantes }\end{array}$ & 18,46 anos \\
\hline Desvio padrão (dp) & 2,005 anos \\
\hline
\end{tabular}

A pesquisa possui uma amostra de 79 adolescentes e jovens de duas escolas públicas do município do Cazenga (Liceu n³049 e Escola n³081), cuja maioria com os pais.

A amostra está constituída maioritariamente por adolescentes e jovens do género masculino $67.1 \%$ $(\mathrm{n}=53)$ e minoritariamente pelo género feminino 32,9\% $(\mathrm{n}=26)$, porem, pela quantidade dividida em género, é possível estabelecermos comparações entre estes grupos de estudantes.

Conforme se observa na Tabela1, quanto a idade, os adolescentes e jovens têm como Idade mínima $=14$ e idade máxima $=25$ anos, possuem idades muito próximas entre eles $\mathrm{dp}=2,005$, sendo a média de idade $=18,46$ anos.

\section{Resultados}

Tabela 2: Distribuição da amostra conforme o começo da vida sexual, histórico da relação sexual nos últimos 12 meses e o uso do preservativo na primeira e na última relação sexual, Luanda/Cazenga, 2019.

?=Não respondeu!

\begin{tabular}{lcccccc}
\multirow{2}{*}{ Variáveis } & \multicolumn{2}{c}{ Masculino } & \multicolumn{2}{c}{ Feminino } & \multicolumn{2}{c}{ Total } \\
\cline { 2 - 8 } & $\mathbf{N}$ & $\mathbf{( \% )}$ & $\mathbf{N}$ & $\mathbf{( \% )}$ & $\mathbf{N}$ & $\mathbf{( \% )}$ \\
\hline Já começou a vida sexual? & & & & & & \\
\hline Total & 53 & 67 & 26 & 33 & 79 & 100 \\
\hline Sim & 46 & 73,1 & 21 & 31,3 & 67 & 84,8 \\
\hline Não & 7 & 58,3 & 5 & 41,7 & 12 & 15,2 \\
\hline Teve relação sexual nos últimos 12 meses? & & & & & & \\
\hline Total & 53 & 67 & 26 & 33 & 79 & 100 \\
\hline Sim & 26 & 74,3 & 9 & 25,7 & 35 & 44,3 \\
\hline Não & 20 & 62,5 & 12 & 37,5 & 32 & 40,5 \\
\hline ? & 7 & 58,3 & 5 & 41,7 & 12 & 15,2 \\
\hline Usou preservativo na 1'arelação sexual? & & & & & & \\
\hline Total & 53 & 29,1 & 26 & 33 & 79 & 100 \\
\hline Sim & 21 & 61,7 & 13 & 38,2 & 34 & 43 \\
\hline
\end{tabular}




\begin{tabular}{lcccccc}
\hline Não & 23 & 74,2 & 8 & 25,8 & 31 & 39,2 \\
\hline$?$ & 9 & 64,3 & 5 & 35,7 & 14 & 17,7 \\
\hline \multicolumn{2}{l}{ Usou preservativo na última relação sexual? } & & & & & \\
\hline Total & 53 & 67 & 26 & 33 & 79 & 100 \\
\hline Sim & 25 & 65,8 & 13 & 34,2 & 38 & 48,1 \\
\hline Não & 19 & 70,4 & 8 & 29,6 & 27 & 34,2 \\
\hline$?$ & 9 & 64,3 & 5 & 35,7 & 14 & 17,7 \\
\hline
\end{tabular}

Fonte: elaboracion propria.

O questionário dirigido a 53 indivíduos da amostra, evidencia que $84,8 \%$ ( $\mathrm{n}=67$ ) destes já começou a vida sexual e 44,3 ( $\mathrm{n}=35$ ) afirmam ter relações nos últimos 12 meses, número significado para nos fornecer dados relactivo as representações sociais sobre relação sexual e o uso do preservativo. No que se refere ao uso do preservativo na primeira e na última relação sexual, $43 \%$ ( $n=34)$ usaram preservativo e $39,2 \%(n=31)$ não usaram o preservativo na primeira relação sexual. Assim, os $74,2 \%(n=23)$ que não usaram preservativo são do sexo masculino e 25,8\% ( $\mathrm{n}=8)$, do feminino. Entretanto, para a última relação sexual, $48 \%(\mathrm{n}=38)$ usaram o preservativo e $34,2 \%(\mathrm{n}=27)$ não usaram o preservativo, dos quais $70,4 \%(\mathrm{n}=19)$ que não usaram preservativo são do sexo masculino e $29,6 \%(n=8)$, do feminino.

\section{Estrutura das representações sociais acerca da relação sexual e do uso do preservativo}

Quadro 1. Distribuição das representações sociais conforme gênero para o estímulo indutor

\begin{tabular}{|c|c|c|c|c|c|c|}
\hline \multicolumn{2}{|c|}{ Núcleo central } & \multicolumn{3}{|c|}{ F Rang Elemento periférico 1} & \multirow{2}{*}{$\begin{array}{c}\mathbf{F} \\
12.9\end{array}$} & \multirow{2}{*}{$\begin{array}{c}\begin{array}{c}\operatorname{Ran} \\
\mathbf{g}\end{array} \\
1.75\end{array}$} \\
\hline Feminino & Bom & 12.9 & 1 & Prazeroso & & \\
\hline Masculino & Bom & 18.35 & 1.35 & Prazeroso & 10.1 & 1.55 \\
\hline \multicolumn{2}{|c|}{ Elemento de contraste } & \multicolumn{5}{|c|}{ Elemento periférico 2} \\
\hline \multirow{4}{*}{ Feminino } & Intimidade & 9.68 & 1.33 & Responsabilidade & 6.45 & 1.5 \\
\hline & Relação & 3.23 & 1 & Amor & 6.45 & 2.5 \\
\hline & Desejo & 3.23 & 1 & Necessidade & 3.23 & 2 \\
\hline & Loucura & 3.23 & 1 & Gostoso & 3.23 & 2 \\
\hline \multirow{4}{*}{ Masculino } & Excitação & 1.83 & 1 & Intimidade & 7.34 & 1.88 \\
\hline & Especial & 1.83 & 1 & Agradável & 5.5 & 2.83 \\
\hline & Mulher & 0.92 & 1 & Gostoso & 4.59 & 1.8 \\
\hline & & & & Amor & 3.67 & 1.75 \\
\hline
\end{tabular}

Fonte: elaboracion propria.

Sobre o Quadro 1, os adolescentes e jovens dos dois géneros descrevem o sexo como algo bom (12-rang 1; 18.35-rang 1.35), e prazeroso (12.9-rang 1.75; 10.1-rang 1.55). Percebe-se que, associado ao termo indutor sexo, os adolescentes e jovens realçaram palavras de intimidade (9.68-rang 1.33; 7.34-rang 1.88), desejo para o género feminino (3.23-rang 1), excitação para o género masculino (1.83-rang 1 ) e amor (6.45-rang 5; 3.67-rang 1.75), revelando que os adolescentes e jovens do género masculino associam sexo à busca de prazer, apenas, diferente do género feminino, que busca por afectividade. 
Quadro 2: Distribuição das representações sociais conforme gênero para o estímulo indutor sexo sem preservativo, Luanda/Cazenga,2019.

\begin{tabular}{|c|c|c|c|c|c|c|}
\hline \multicolumn{2}{|c|}{ Núcleo central } & \multirow{2}{*}{\begin{tabular}{l}
\multicolumn{1}{c}{$\mathbf{F}$} \\
14.63 \\
12.2
\end{tabular}} & \multirow{2}{*}{$\begin{array}{l}\text { Rang } \\
1.33 \\
1.6\end{array}$} & Núcleo periférico 1 & \multirow{2}{*}{$\begin{array}{r}\mathbf{F} \\
19.52\end{array}$} & \multirow{2}{*}{$\begin{array}{l}\text { Rang } \\
2.25\end{array}$} \\
\hline Feminino & $\begin{array}{l}\text { Perigo } \\
\text { Gravidez }\end{array}$ & & & Doença & & \\
\hline Masculino & Bom & 11.11 & 1.33 & $\begin{array}{l}\text { Doença } \\
\text { Gravidez } \\
\text { Perigoso }\end{array}$ & $\begin{array}{l}16.67 \\
12.96 \\
12.04\end{array}$ & $\begin{array}{l}1.83 \\
1.64 \\
1.85\end{array}$ \\
\hline Eleme & le contraste & & & Elemento periférico 2 & & \\
\hline Feminino & $\begin{array}{l}\text { HIV } \\
\text { Bom } \\
\text { Prejudicial } \\
\text { Apetece }\end{array}$ & $\begin{array}{l}4.88 \\
4.88 \\
4.88 \\
2.44\end{array}$ & $\begin{array}{l}1 \\
1 \\
1 \\
1\end{array}$ & $\begin{array}{l}\text { Prazeroso } \\
\text { Errado } \\
\text { Agradável } \\
\text { Gostoso }\end{array}$ & $\begin{array}{l}4.88 \\
4.88 \\
4.88 \\
2.44\end{array}$ & $\begin{array}{l}2 \\
2 \\
2 \\
3\end{array}$ \\
\hline Masculino & $\begin{array}{l}\text { Prejudicial } \\
\text { Errado } \\
\text { Não }\end{array}$ & $\begin{array}{l}2.78 \\
0.93 \\
0.93\end{array}$ & $\begin{array}{l}1 \\
1 \\
1\end{array}$ & $\begin{array}{l}\text { HIV } \\
\text { Prazeroso } \\
\text { Agradável } \\
\text { Mal }\end{array}$ & $\begin{array}{l}9.26 \\
6.48 \\
5.56 \\
2.78\end{array}$ & $\begin{array}{l}1.9 \\
2.14 \\
2.17 \\
1.67\end{array}$ \\
\hline
\end{tabular}

Fonte: elaboracion propria.

O Quadro 2 revela que os adolescentes e jovens têm consciência dos perigos do não uso do preservativo, associando este termo indutor com perigo, gravidez, doença, HIV. Pode-se ver que a gravidez faz parte do núcleo central feminino, mostrando que o género feminino está em alerta e preocupado com o aumento da natalidade entre os adolescentes.

Quadro 3: Distribuição das representações sociais conforme gênero para o estímulo indutor sexo com preservativo, Luanda/Cazenga, 2019.

\begin{tabular}{|c|c|c|c|c|c|c|}
\hline \multicolumn{2}{|c|}{ Núcleo central } & F & Rang & Núcleo periférico 1 & F & Rang \\
\hline Feminino & $\begin{array}{l}\text { Protecção } \\
\text { Segurança } \\
\text { Melhor }\end{array}$ & $\begin{array}{l}37.21 \\
6.98 \\
6.98\end{array}$ & $\begin{array}{l}1.69 \\
1 \\
1.67\end{array}$ & Evita doença & 6.98 & 2.33 \\
\hline Masculino & Desagradável & 12.5 & 1.15 & $\begin{array}{l}\text { Protecção } \\
\text { Evita doença }\end{array}$ & $\begin{array}{l}25.96 \\
12.5\end{array}$ & $\begin{array}{l}1.44 \\
2.38\end{array}$ \\
\hline Elemer & de contraste & & & Elemento periférico 2 & & \\
\hline Feminino & $\begin{array}{l}\text { Bom } \\
\text { Gostoso } \\
\text { Prevenção } \\
\text { Agradável }\end{array}$ & $\begin{array}{l}4.65 \\
4.65 \\
2.33 \\
2.33\end{array}$ & $\begin{array}{l}1 \\
1.5 \\
1 \\
1\end{array}$ & $\begin{array}{l}\text { Cuidado } \\
\text { Prejudicial } \\
\text { Aconselhável } \\
\text { Prazeroso }\end{array}$ & $\begin{array}{l}4.65 \\
2.33 \\
2.33 \\
2.33\end{array}$ & $\begin{array}{l}2.5 \\
2 \\
2 \\
2\end{array}$ \\
\hline Masculino & $\begin{array}{l}\text { Bom } \\
\text { Saudável }\end{array}$ & $\begin{array}{l}5.77 \\
0.96\end{array}$ & $\begin{array}{l}1.33 \\
1\end{array}$ & $\begin{array}{l}\text { Evita gravidez } \\
\text { Melhor } \\
\text { Segurança } \\
\text { Gostoso }\end{array}$ & $\begin{array}{l}8.65 \\
6.73 \\
3.85 \\
3.85\end{array}$ & $\begin{array}{l}2.22 \\
1.86 \\
2 \\
2\end{array}$ \\
\hline
\end{tabular}

Fonte: elaboracion propria.

Os adolescentes e jovens associam uso de preservativo na relação sexual com proteção, segurança e que prevenção de doenças, demostrando que possuem informações sobre os perigos do não uso do preservativo, porém, os rapazes, referem-se ao uso do preservativo, no acto sexual, como uma prática desagradável que diminui o prazer sexual.

\section{Discussão}


Quanto o início da vida sexual, a média foi de 13,84 anos, número superior ao que Soares et al. (2015) encontraram no seu estudo. Os dados revelaram que $84,8 \%(n=67)$ dos adolescentes e jovens já começaram a vida sexual e 44,3 (n=35) afirmam ter relações nos últimos 12 meses.

No que se refere ao uso do preservativo na primeira e na última relação sexual, $74,2 \%$ ( $n=23$ ) são do sexo masculino, confirmando que o género masculino, entre adolescentes e jovens, está mais propenso a adquirir doenças sexualmente transmissíveis.

Para o termo indutor sexo, os adolescentes e jovens dos dois géneros, relacionam sexo com prazer, demostrando uma desinibição e falta de tabus da sociedade em relação ao sexo, principalmente no que diz respeito ao género feminino, corroborando com Vieira et al. (2016) quando afirmam que as mulheres estão mostrando seus "desejos" e estão "assumindo" um papel importante nas relações sociais.

Essa nova forma de ver a sexualidade, segundo os estudos de Rodrigues et al. (2016) parte das transformações globais, do uso da tecnologia e pela democratização da informação. Estes conteúdos explícitos, relactivos a sexualidade, imposto aos adolescentes pelo "mundo novo", pedese a escola uma intervenção não tão "moralista" nem muito "banalizada".

Ligadas ao prazer, estão as palavras intimidade, desejo, excitação e amor, elementos indispensáveis e relacionados com resultados semelhantes aos encontrados por Bezerra et al. (2015).

Silva e Costa (2019) ao estudarem as representações de mulheres encarcerada, verificaram que palavras como: Amor, Desejo, Prazer, Sexo, Pênis, Carinho, Excitação, Penetração e Paixão faziam parte das representações destas mulheres. Sendo amor, desejo e prazer as palavras com maior ocorrência, revelando a representação de sexualidade entre essas mulheres encarceradas. Porém, termos como excitação e penetração surgiam devido ao tempo em que se encontravam privadas de "visitas íntimas" e outros termos como carinho, e paixão demostravam afectividade e intimidade em relação ao sexo, mesmo em ambiente não propício.

O não uso do preservativo foi associado ao perigo, gravidez, doença, HIV, sendo a palavra HIV referenciada por ambos os géneros, de acordo com o estudo realizado por Rodrigues et al. (2011), as representações sociais dos adolescentes sobre HIV estão relacionadas com aspectos negativos como o medo e a discriminação. Enquanto que para Hilário et al. (2019), os adolescentes relacionam gravidez precoce e não planeada com abandono dos estudos, "projectos de vida" e das interacções "sociais e familiares".

O medo, pelos transtornos causados, pelo não uso do preservativo, evidencia também um conhecimento prévio desses estudantes sobre questões relacionada com a sexualidade. A pesquisa de Rezende e Sobral (2016) afirma que os conteúdos sobre a sexualidade humana, ainda que de forma "modéstia", estão a ser transmitidos, sendo a educação sexual muito importante, pois envolve a "saúde orgânica e comportamental"

Por outro lado, no estudo de Michel Morin sobre as práticas de prevenção dos "jovens" versus o risco representado pelo SIDA, termo como HIV foi relacionado com doença, morte e rejeição social, porém junto de palavras como amor, confiança e liberdade sexual. Semelhante aos nossos resultados (prazer, agradável, gostoso) (Abric, 2001). Vista neste ângulo, Abric e Flamet, esclarecem que o HIV não contitui uma representação independente, pois entra numa esfera denominada de "conflito de representação", isto é em relação ao "comportamento exigido", "comportamento declarado" e pelo facto de que no acto sexual a pessoa portar ou não o preservativo (Abric, 2001).

Costa (2019) defende em sua pesquisa, que o conflito entre o não uso do preservativo ser algo prazeroso, agradável, gostoso e ao mesmo tempo ser algo perigoso, associado a gravidez e DSTs como o Sida é reforçada pela omnipotência na adolescência, um sentimento que faz os adolescentes acreditarem que com eles nunca vai ocorrer coisa negativa, estado "imunes" a qualquer ameaça.

Sobre o género dos adolescente e uso do preservativo nas relações sexuais, os adolescentes e jovens possuem informações sobre os perigos do não uso do preservativo, porém, os rapazes, encaram o uso do preservativo como uma prática desagradável que reduz o prazer sexual ao contrário as 
meninas que o percepcionam como perigoso, medonho. O inverso ocorreu na pesquisa de Valim et al. (2015), onde o género feminino classificou o uso do preservativo como algo inconveniente.

\section{Considerações Finais}

A sexualidade, envolve uma área abrangente, como os aspectos biológicos e os psicológicos, na sexualidade encontramos o prazer, erotismo, o afecto, as relações e toda variável qualitativa e quantitativa do prazer. Nesta fase, aparece um estímulo interno forte para estabelecer relações com os outros, mormente para a consumação do acto sexual.

A actividade sexual leva os adolescentes e os jovens a enfrentarem diversos problemas como a gravidez indesejada, doenças sexualmente transmissíveis, exploração sexual e baixa autoestima. Embora a sexualidade seja um tema de extrema importância, raramente é debatida no seio familiar, e pelo contrário, deixado à mercê dos amigos dos adolescentes-jovens e da mídia. Na nossa opinião, sendo a escola, um lugar onde a maior parte dos adolescentes e jovens passam o tempo, a sexualidade, neste local, deveria ser debatida com frequência, pois é um espaço de desenvolvimento de habilidades importantes para os adolescentes e jovens.

Em síntese, a presente pesquisa teve como objetivo, conhecer a estrutura das representações sociais sobre a relação sexual e uso de preservativo em adolescentes e jovens. De acordo com os resultados obtidos, os adolescentes e jovens dos dois géneros, relacionam sexo com prazer, intimidade, desejo, excitação e amor.

Outrossim, o não uso do preservativo foi associado ao perigo, gravidez, doença, HIV. E nos foi possível aferir que os adolescentes e jovens possuem informações sobre os perigos do não uso do preservativo, porém, os rapazes, relacionam o uso do preservativo como uma prática desagradável que diminui o prazer do sexo.

A média de idade para o começo da vida sexual, da nossa amostra, foi de 13 anos. Notamos, ainda, que $74 \%$ dos adolescentes e jovens do género masculino não usaram preservativo na primeira e na última relação sexual. Os adolescentes e jovens do género masculino associam sexo à busca de prazer enquanto que o género feminino relacionam sexo com a busca por afectividade.

Foi também notável a associação, por parte do género feminino, de relação sexual desprotegida com gravidez. Todavia, o uso do preservativo na relação sexual foi relactada como uma prática segura, em contrapartida pouco agradável.

Portanto, em nosso entender, conhecer as representações dos adolescentes e jovens sobre sexo permite aos profissionais e as instituições, políticas identificar barreiras, quebrar tabus e educar para a saúde deste grupo, levando em conta os aspectos sociais, locais de interacção, ambientes sociais, "formação e intervenção", bem como os aspectos familiares "influenciados" pelo meio social e cultural.

Por ser um estudo de caracter exploratório, deveria ampliar-se a amostra para mais escolas da rede pública, utilizando-se da amostragem probabilistica e podendo fazer estudo comparativo com escolas privadas para, então, perceber-se a diferença entre estas escolas e a eficácia ou implementação de políticas utilizadas.

\section{Referências bibliográficas}

Abric, Jean-Claude. (2001). Pratiques sociales y Représentations. Filosofia e Cultura Contemporânea. No. 16 (Pp.1-140) Extraido de http://webcache.googleusercontent.com/search?q= cache:jrOX4wWaWhUJ:villaeducaci on.mx/descargar.php $\% 3$ Fidtema $\% 3 \mathrm{D} 1337 \% 26 \mathrm{data} \% 3 \mathrm{D} 262 \mathrm{dc} 7$ practicas-socialesfull.pdf $+\& c d=1 \& h l=p t-P T \& c t=c \ln k \& g l=$ ao\&client $=$ firefox $-b-d$

Abric, Jean-Claude. (2016). Las Representaciones Sociales: Aspectos Teoricos. Extraido de https://campus.fundec.org.ar/admin/archivos/ABRIC $\% 20-\% 20$ practicas-sociales-yrepresentaciones-5-16.pdf 
Almeida, Angela Maria de Oliveira. (2009). Abordagem Societal das Representações Sociais. Sociedade e Estado, Brasília. Volume 24, No. 3 (Pp.713-737). Extraido de www.scielo.br/pdf/se/v24n3/05.pdf

Aquino, Julio Groppo. (1997). Sexualidade na escola. (quarta edición). Editora Grupo Editorial Summus. Brasil.

Batista, Carina do Céu Gomes. (2006). Representações Sociais construídas pelos Professores de Adolescentes Institucionalizadas. Tese de Licenciatura. Licenciatura em Serviço Social. Universidade Fernando Pessoa. Portugal.

Bezerra, Elys de Oliveira. Pereira, Maria Lúcia Duarte ., Chaves, Ana Clara Patriota \& Monteiro, Priscila de Vasconcelos. (2015). Representações sociais de adolescentes acerca da relação sexual e do uso do preservativo. Rev Gaúcha Enferm. Volume 36, No. 1. (Pp. 84-91). https://doi.org/10.1590/1983-1447.2015.01.45639

Campagna, Viviane Namur. (2005). Identidade Feminina No Inicio Da Adolescencia. Editora Casa dos Psicólogos. Brasil.

Costa, Rodrigo César. (2019). A inclusão da orientação sexual na escola: possibilidades de esclarecimento da sexualidade para os jovens. Revista Científica Multidisciplinar Núcleo do Conhecimento. Volume 09,No. 1. (Pp. 56-65). Extraido de https://www.nucleodoconhecimento.com.br/psicologia/possibilidades-deesclarecimento

Cristo, Hugo. (2019). OpenEvoc 0.84 Extraido de http://www.hugocristo.com.br/projetos/openevoc/index.php?msg=4

Doise, Willem. (2002). Da Psicologia Social à Psicologia Societal. Psicologia: Teoria e Pesquisa. Volume 18, No. 1. (Pp. 027-035). Extraido de http://www.scielo.br/pdf/ptp/v18n1/a04v18n1

Durkheim, Émile. (2007). As regras do método sociológico. (terceira edición). Editora Martins Fontes. Brasil.

Hilário, Carolina Casagrande., Takeshita, Isabel Mie., Eto, Gabriela de Moura., Rosignoli, Jordana Bernardes., Sntos, Lidiane Pereira de Sousa \& Moura, Luciana Ramos de. (2019). Saúde sexual e reprodutiva: troca de experiências entre adolescentes e acadêmicas. Revista Científica Multidisciplinar Núcleo do Conhecimento. Volume 10, No. 6 (Pp.90-106). Extraido de https://www.nucleodoconhecimento.com.br/saude/saude-sexual

Itoz, Sonia. (2012). Adolescência e Sexualidade Para Eles e Para Nós. (oitava edición). Editora Paulinas. Brasil.

Jodelet, Denise. (2001). Representações sociais: um domínio em expansão. Em Jodelet, Denise. As representações sociais. Editora da Universidade do estado do Rio de Janeiro. Brasil.

Jovchelovitch, Sandra. (2000). Representações sociais e esfera pública: a construção simbólica dos espaços públicos no Brasil. Editora Vozes. Brasil.

Manning. Sydney A. (1993). O Desenvolvimento Da Criança E Do Adolescente. Editora Cutrix. Brasil.

Mendonça, Anderson Pereira \& Lima, Marcos Eugênio Oliveira. (2014). Representações sociais e cognição social. Psicologia e Saber Social. Volume 3, No. 2. (Pp. 191-206). Extraido de https://www.e-publicacoes.uerj.br/index.php/psi-sabersocial/article/view/14470/10949

Moscovici, Serge. (2007). Representações sócias: investigações em psicologia social. (quinta ededición). Editora Vozes. Brasil.

Myers, David G. (2014). Psicologia Social. (décima edición). Editora AMGH. Brasil.

Neto, Othon Cardoso Melo e Cerqueira-Santos, Elder. (2012). Comportamento Sexual e Autoestima em Adolescentes. Contextos Clínicos. Volume 5. No.2 (Pp. 100-111).

Oliveira, Denize Cristina. Gomes, Antônio Marcos Tosoli., Pontes, Ana Paula Munhen \& Salgado, Luiz Phillipi Porto. (2009). A Representação Social da sexualidade entre adolescentes. Esc Anna Nery Rev Enferm. Volume 13. No.4 (Pp. 817-23). Extraido de https://core.ac.uk/download/pdf/207016032.pdf 
Prodanov, Cleber Cristiano. \& Freitas, Ernani Cesar. (2013). Metodologia do trabalho científico: métodos e técnicas da pesquisa e do trabalho académico. (segunda edición). Editora Feevale. Novo Hamburgo. Brasil.

Queiroz, Maria Amélia Crisóstomo., Lourenço, Rejane Martins Enéas., Coelho, Manuela de Mendonça Figueirêdo., Miranda, Karla Corrêa Lima., Barbosa, Rachel Gabriel Bastos. \& Bezerra, Sara Taciana Firmino. (2015). Representações sociais da sexualidade entre idosos. Rev Bras Enferm. Volume 68, No. 4. (Pp. 662-7). Extraido de https://www.scielo.br/pdf/reben/v68n4/0034-7167-reben-68-04-0662.pdf

Rezende, Anyelle Vasconcelos \& Sobral, Osvaldo José. (2016). As temáticas relativas à sexualidade humana na formação superior do profissional de enfermagem. Revista Científica FacMais. Volume 5. No.1 (Pp. 26-39). Extraido de https://revistacientifica.facmais.com.br/wp-content/uploads/2016/06/2-

$\% 20 \mathrm{As} \% 20$ tem $\%$ C $3 \%$ A 1 ticas $\% 20$ relativas $\% 20 \%$ C $3 \%$ A $0 \% 20$ sexualidade $\% 20$ humana $\% 2$ Ona $\% 20$ forma $\%$ C $3 \%$ A $7 \%$ C3 $\%$ A $30 \% 20$ superior $\% 20$ do $\% 20$ profissional $\% 20$ de $\% 20$ Enfer magem.pdf

Ribeiro, Cristiane G., Coutinho, Maria da Penha L. \& Saldanha, Ana Alayde W. (2004). Estudo das representações sociais sobre a aids por profissionais de saúde que atuam no contexto da soropositividade para o HIV. DST - J bras Doenças Sex Transm. Volume 16. Nº. (Pp. 14-18). Extraido de http://www.dst.uff.br/revista16-4-2004/3.pdf

Rodrigues, Andreia Filipa Duarte de Jesus. (2010). Sexualidade na adolescência: atitudes e Conhecimentos sobre métodos contraceptivos. Dissertação de Mestrado. Dissertação de Mestrado. Mestrado em Psicologia. Especialidade de Psicologia Clínica. Instituto Universitário. Portugal.

Rodrigues, Andréia Silva. Jesus, Michele Cunha de., Silva, Lucineide Santos., Oliveira, Jeane Freitas de., Paiva, Mirian Santos. (2011). Representações sociais de adolescentes e jovens vivendo com HIV acerca da adolescência, sexualidade e AIDS. Rev. Eletr. Enf. [Internet]. $\begin{array}{llllll}\text { Volume } & 13 . & \text { No.4 } & \text { (Pp. 680-7). }\end{array}$ https://www.revistas.ufg.br/fen/article/view/12815/10216

Rodrigues, Beatriz. (2016). Sexualidade Infantil: Desafios da Escola Contemporânea. Revista Científica Multidisciplinar Núcleo do Conhecimento. Volume 8. (Pp. 17-28). Extraido de https://www.nucleodoconhecimento.com.br/pedagogia/sexualidade-infantil

Sá, Celso Pereira de. (1996). Núcleo central das representações sociais. (segunda edición). Editora Vozes. Brasil.

Silva, Cherla Mabene Lima da \& Costa, Ceres Neide Almeida. (2019). Sexualidade da mulher privada de liberdade: sentimentos e necessidades. Revista Científica Multidisciplinar Núcleo do Conhecimento. Volume 03, No. 12. (Pp. 114-122). Extraido de https://www.nucleodoconhecimento.com.br/saude/mulher-privada-de-liberdade

Simões, Aníbal João Ribeiro. (2015). Representações Sociais Sobre a Inclusão Social dos Jovens Angolanos Residentes em Luanda. Faculdade de Ciências Sociais da Universidade Agostinho Neto. Angola.

Soares, Leonardo Ribeiro., Cabero, Flávia Vidal., Souto, Thays Garcia., Coelho, Rui Flávio de Souza., Lacerda, Luciene Cunha Monteiro \& Matão, Maria Eliane Liégio. (2015). Avaliação do comportamento sexual entrejovens e adolescentes de escolas públicas, Adolescência \& Saúde. Volume 12. No.2. (Pp. 76-84). Extraido de https://cdn.publisher.gn1.link/adolescenciaesaude.com/pdf/v12n2a09.pdf

Vala, Jorge \& Monteiro, Maria Benedita. (1993). Representações sociais - para uma psicologia social do pensamento social. Em Vala, J. \& Monteiro, Psicologia Social. Editora Fundação Calouste Gulbenkian. Portugal.

Valim, Edna Maria Alves., Dias, Flavia Aparecida., Simon, Cristiane Pauli., Almeida, Débora Vieira de., Rodrigues, Maria Laura Pinto. (2015). Utilização de preservativo masculino entre adolescentes de escolas públicas na cidade de Uberaba (MG), conhecimentos e atitudes, 
Cad. Saúde Colet. Volume 23. No.1. Brasil (Pp. 44-9). Extraido de https://www.scielo.br/pdf/cadsc/v23n1/1414-462X-cadsc-23-01-00044.pdf

Vieira, Kay Francis Leal., Arruda, Maria Valdênia Soares., Nóbrega, Renata Pires Mendes da., Veiga, Priscila Monique de Melo. (2016). Representação Social das Relações Sexuais: um Estudo Transgeracional entre Mulheres. Psicologia: Ciência e Profissão. Volume 36. No.2. (Pp. 329-340). Extraido de https://www.scielo.br/pdf/pcp/v36n2/1982-3703-pcp36-2-0329.pdf

Zampieri, Maria Cristina. (2004). O Sexo Da Universidade: um estudo sobre a sexualidade e o comportamento sexual do adolescente universitário. Editora Arte e ciência. Brasil. 